\title{
THE CLINICAL AND RADIOLOGICAL ASSESSMENT OF THE PULMONARY ARTERIAL PRESSURE IN MITRAL STENOSIS
}

\author{
BY \\ L. G. DAVIES, J. F. GOODWIN, R. E. STEINER, AND \\ B. D. VAN LEUVEN \\ From the Departments of Medicine and of Radiology, Postgraduate Medicat School of London
}

Received June 22, 1953

The frequent association of pulmonary hypertension with symptomatic mitral stenosis has stimulated much investigation concerning its significance and the mechanism of its production. Two types are now recognized: passive hypertension, where the increased pressure in the left atrium and pulmonary veins and capillaries produced by the stenosed mitral valve is transmitted to the pulmonary artery; and active hypertensions, where much higher levels of pulmonary arterial pressure are due to an increased vascular resistance in the lungs (Bayliss et al., 1950a; Eliasch, 1952; Lewis et al., 1952). The causes of this increase in vascular resistance are not fully understood, but Parker and Weiss (1936), Larabee et al. (1949), Henry (1952), and Harrison (1953) have found thickening of the walls of the small pulmonary arteries, while Dexter et al. (1950), Holling (1952), and Ball et al. (1952) have suggested that reversible vasoconstriction may also occur. Angio-cardiography has demonstrated narrowing and irregularity of the smaller pulmonary arteries in patients with symptomatic mitral stenosis (Goodwin et al., 1952; Actis-Dato et al., 1952). The present investigation was undertaken to determine the significance of these changes, whether they could be detected on plain radiographs, and whether they were proportional to the pulmonary arterial pressure. The value of the symptoms, physical findings, and electrocardiographic signs, in estimating pulmonary arterial pressure was assessed by comparing them with the pressures measured by cardiac catheterization. An attempt was made to determine which of these methods provided the best estimate of the pressure.

\section{MeTHODS}

Fifty-one patients suffering from mitral stenosis of varying severity were studied. The series included patients with normal pulmonary arterial pressures and with all degrees of pulmonary hypertension. Thirty-five patients had aortic valve disease, but in all these mitral valve disease was the dominant lesion. Mitral incompetence, in association with stenosis, was diagnosed in 10 subjects, and in 4 of these was thought to be of greater hæmodynamic importance than stenosis. One patient had systemic hypertension in addition to mitral stenosis. Dyspnœa was graded according to the classification of the New York Heart Association (1939).

The clinical classification of pulmonary hypertension was as follows. Grade $O$ : normal left ventricular impulse, normal second sound in the pulmonary area. Grade I: tapping impulse, gentle sternal lift, narrow splitting of the second heart sound with slight accentuation of the pulmonary element. Grade II: tapping impulse, marked sternal heave, narrow splitting of the second heart sound with more accentuation of the pulmonary element. A systolic murmur over the pulmonary area and a triple rhythm were not found frequently enough to be of diagnostic value. 
Cardiographic evidence of right ventricular hypertrophy was graded as follows. Grade $O$ : normal ventricular complexes with or without abnormal $\mathrm{P}$ waves or auricular fibrillation. Grade I: clockwise rotation ( $R$ smaller than $S$ in V5), predominant $R$ wave in aVR and in V4R, incomplete right bundle branch block. Grade II: $\mathrm{R}$ wave greater than $\mathrm{S}$ wave in V1, with ventricular activation time greater than 0.03 per second in V1; $R$ wave smaller than $S$ wave in V5, predominant $\mathbf{R}$ wave in aVR.

Cardiac Catheterization. Systolic and diastolic pressures in the pulmonary artery (or right ventricle) in the resting state were measured by strain gauge manometer in 43 patients by the technique of Bayliss et al. (1950b), the maximum normal pressure being $30 / 15 \mathrm{~mm}$. $\mathrm{Hg}$.

Angiocardiography. Venous angiocardiograms were performed in 22 patients by the technique previously described (Goodwin et al., 1952). Selective pulmonary arteriograms were carried out in a further 9 patients as follows: after sedation, a number 9 cardiac catheter was introduced into the right (or left) main pulmonary artery and the pressure measured. After an injection of atropin (1/100 of a grain), anæsthesia was induced by intravenous pentothal and maintained with gas, oxygen, and trilene. Twenty $\mathrm{ml}$. of 70 per cent solution of diodone was injected through the catheter by means of a manually operated pressure pump. The radiographic technique was identical with that used for venous angiocardiography.

No adverse reaction occurred in any patient as a result of the injection of contrast medium into the pulmonary artery. Care was taken to ensure that the tip of the catheter did not pass beyond the right or left main pulmonary artery. General anæsthesia diminished the possibility of pulmonary artery spasm, sudden coughing, or movement. Venous angiocardiography was uneventful in all except one patient. This was a woman of 49 years with severe mitral stenosis and pulmonary hypertension, whose condition gave rise to no anxiety during or immediately after the angiocardiogram, but shortly after return to the ward she became cyanosed and pulseless, and died suddenly: there had been no reaction to a test dose of diodone. Autopsy confirmed the clinical diagnosis and there were widespread and severe occlusive changes in the smaller pulmonary arteries and arterioles. Pulmonary odema was absent, and the exact cause of sudden death could not be ascertained.

\section{RESULTS}

Angiocardiographic Appearances. As has been previously described (Goodwin et al., 1952) the pulmonary arteries presented a distinctive appearance in patients with pulmonary hypertension. Enlargement of the main arteries was associated with narrowing, tortuosity, and irregularity of the peripheral branches, mainly at the bases, but more widespread when pulmonary hypertension was severe. In patients with normal pulmonary arterial pressures or a minimal increase, the main pulmonary arteries were normal or slightly enlarged and the peripheral branches appeared normal or showed minimal changes. The pulmonary veins were usually normal but sometimes enlarged. Selective pulmonary arteriograms demonstrated the arterial changes more clearly than did the venous angiocardiograms. The appearances of the left atrium have been noted elsewhere (Steiner and Goodwin, 1953) and will not be further mentioned here.

The Appearances of the Lungs on plain Radiographs. The main pulmonary arteries were found to be enlarged in patients with pulmonary hypertension, and as in the angiocardiograms, the peripheral branches were seen to be narrowed, predominantly at the bases (Fig. 1). The pulmonary veins were visible in some films, but were not sufficiently clearly outlined to permit any conclusions to be drawn. A fine mottling of the lung fields (Fig. 2), which from a study of the angiocardiograms did not appear to be arterial or venous in nature, was usually associated with significantly increased pulmonary arterial pressure. This mottling was enough in 16 patients to warrant the diagnosis of hæmosiderosis, the systolic pulmonary arterial pressure being above $100 \mathrm{~mm}$. $\mathrm{Hg}$ in 5 of them, between 50 and 100 in 6, between 30 and 50 in 3, normal in one, and not measured in one. In 10 patients fine horizontal striations at the bases of the lungs in the region of the costophrenic angle were seen, similar to those ascribed to engorged lymphatic channels by Kerley (1951). 


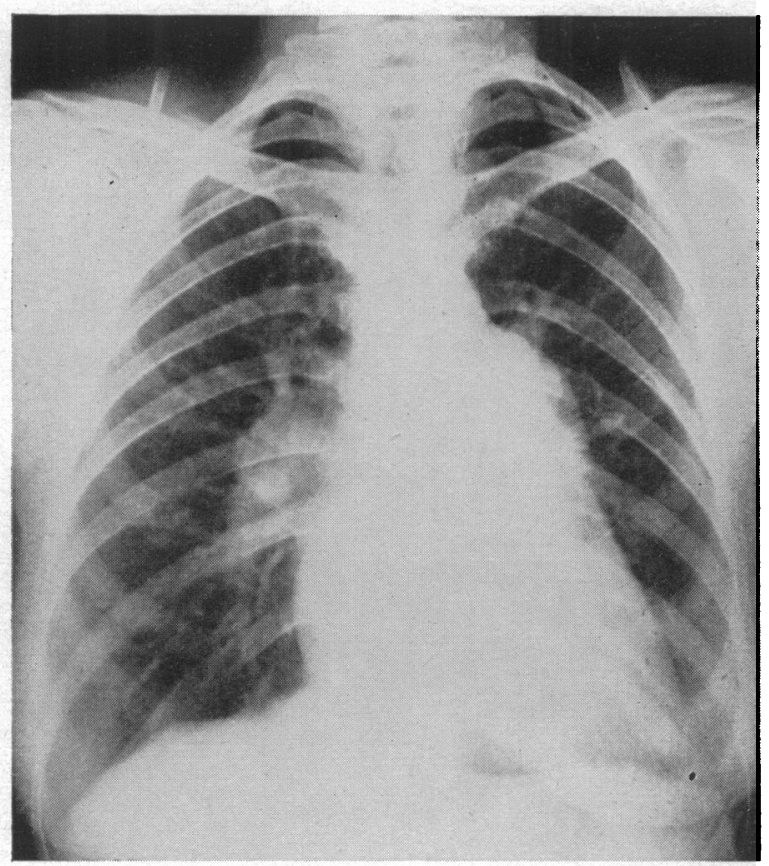

FIG. 1.-Six-foot postero-anterior radiograph of patient with severe pulmonary hypertension (P.A. pressure $130 / 70 \mathrm{~mm}$. Hg). Great enlargement of main pulmonary artery and major branches, with narrowing and irregularity of peripheral branches.

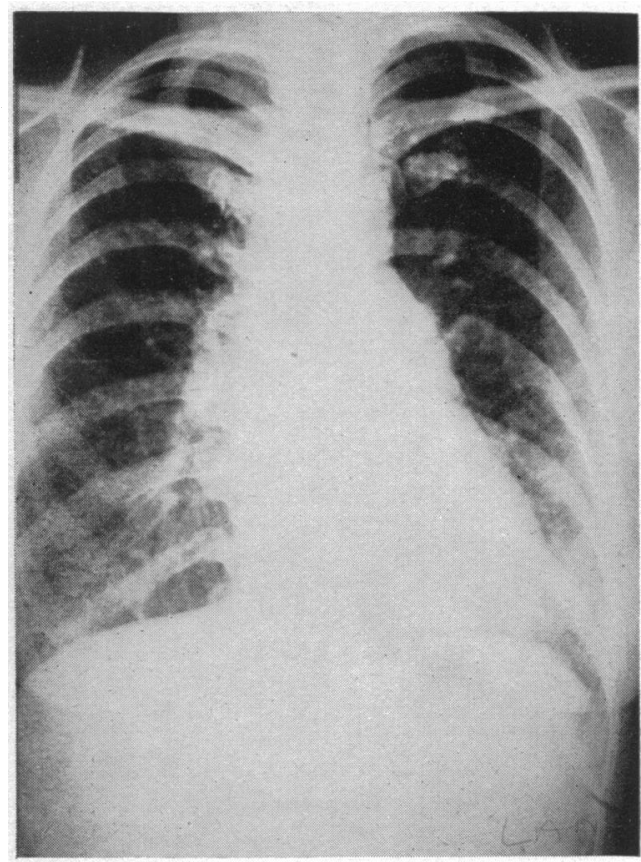

Fig. 2.-Six-foot postero-anterior radiograph of patient with pulmonary arterial pressure of $100 / 50 \mathrm{~mm}$. $\mathrm{Hg}$. Enlargement of main pulmonary artery and major branches, with narrowing of peripheral branches. Fine mottling in lower and mid zones of lungs.

The Comparison between the Angiocardiographic and the plain Radiographic Appearances of the Pulmonary Arteries. The appearances in angiocardiogram and plain film of the main pulmonary arteries and the first, second, and third divisions were compared in each of 22 patients, having regard to whether the branches were narrowed, normal, or enlarged. Fig. 3 shows that there was a positive correlation, most of the changes demonstrated angiocardiographically being detected on the straight film. Comparison was more difficult in those with moderately raised pressures than those with normal pressure or with severe pulmonary hypertension. Correlation between the angiocardiographic appearances and the straight radiographs was equally good in the 9 patients examined by angiocardiography or pulmonary arteriography, in whom the pulmonary arterial pressure was not measured.

The correlation was sufficiently good to permit the severity of the arterial changes to be graded by examination of the plain radiograph. Three grades of pulmonary arterial change were recognized:

Grade $O$, normal (Fig. 4 A and B); Grade I, enlargement of the main pulmonary artery, including the first divisions, with narrowing and tortuosity of the distal branches, the changes being confined to the bases of the lungs (Fig. 5 and 6); and Grade II, marked enlargement of the main pulmonary artery and main branches with more widespread peripheral changes (Fig. 7 and 8). The plain radiographs were assessed with consistent results by each of the authors separately.

The grade of arterial change in relation to the pulmonary arterial pressure in each subject in whom angiocardiography was carried out, can be seen in Fig. 3. Fig. 9 shows the arterial changes seen on plain radiographs, in a control series of 21 subjects upon whom angiocardiography was not performed, arranged in order of ascending systolic pulmonary arterial pressures. In both groups of patients the highest pulmonary arterial pressures tended to be associated with Grade II arterial 


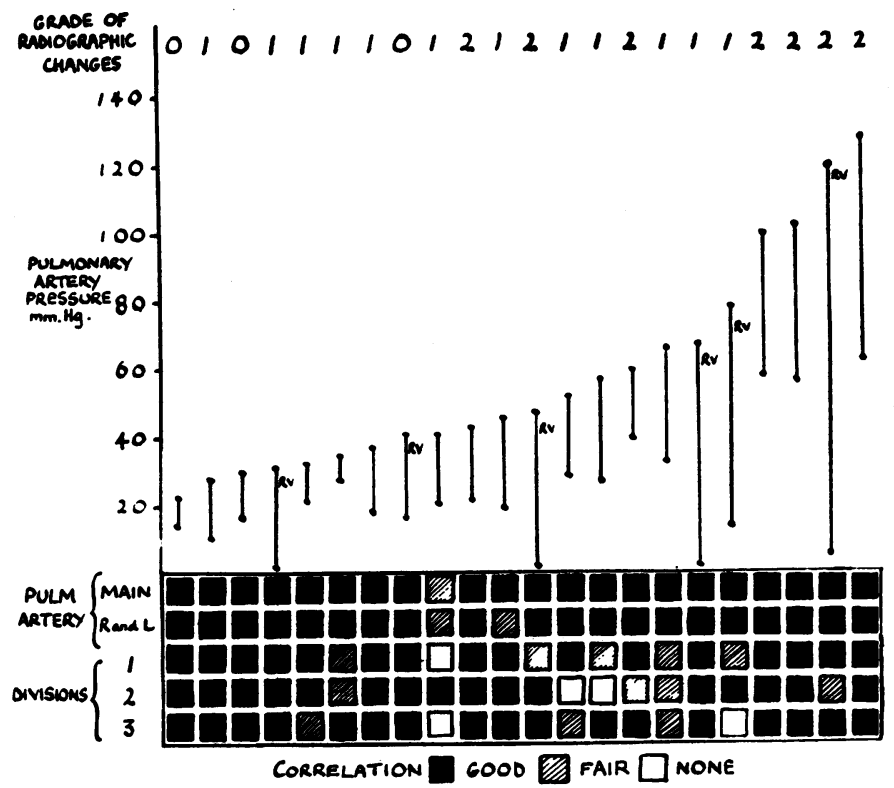

FIG. 3.-Comparison between the pulmonary arterial pressure and the angiocardiographic and the plain film appearances of the pulmonary arteries in 22 patients with mitral stenosis. In each, the appearances of the pulmonary arterial tree on the plain radiograph have been compared with the angiocardiogram, using the latter as a standard. The comparison between each branch in each patient is shown in the block diagram. The grade of arterial change as seen on the plain film in each case is shown at the top of the chart.

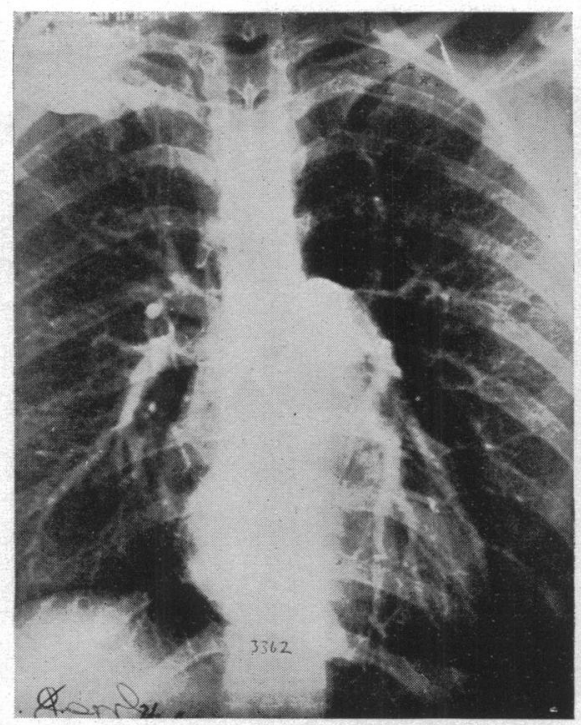

A

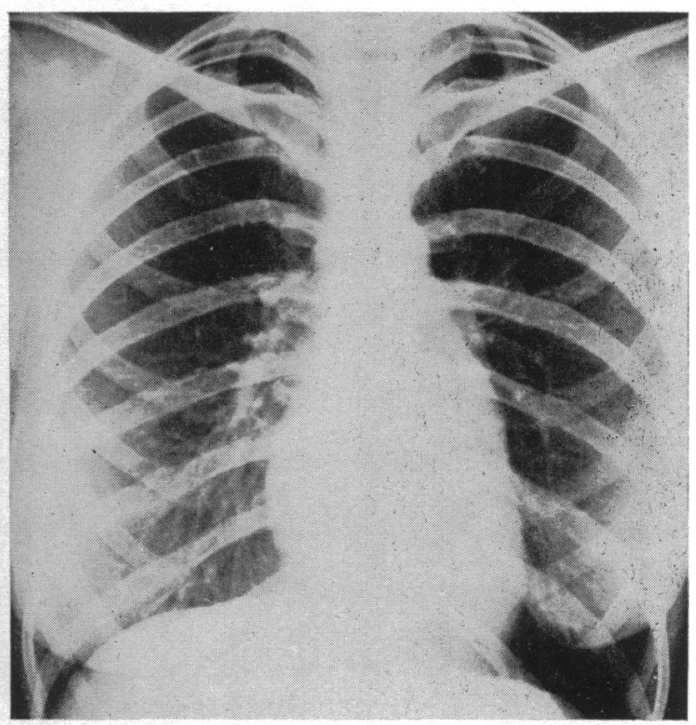

B

FIG. 4.-(A) Venous angiocardiogram of patient with mitral stenosis but without pulmonary hypertension. The pulmonary arterial tree is normal, except for slight enlargement of the main trunk. (B) Six-foot postero-anterior radiograph of the same patient. The slight enlargement of the main pulmonary artery and the normal peripheral branches can be clearly seen. 


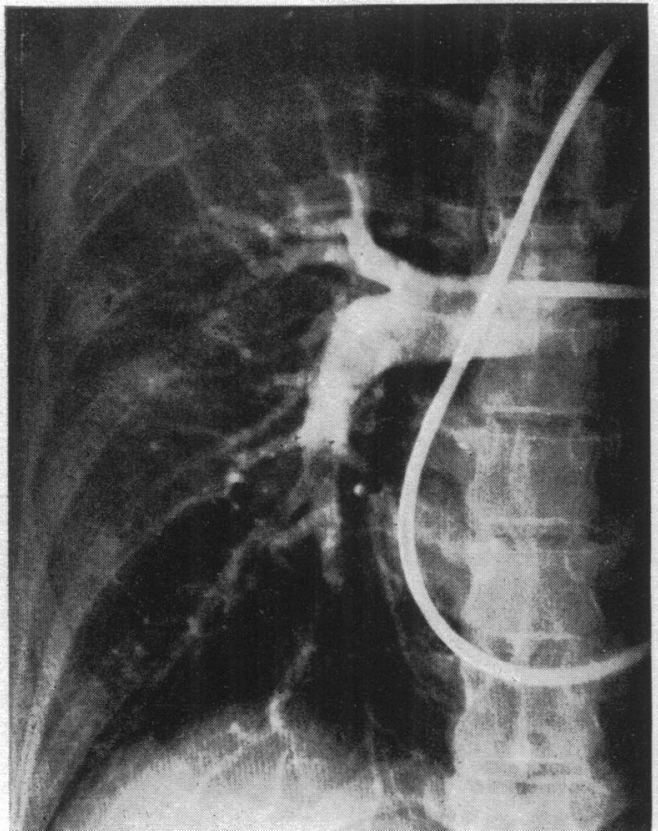

A

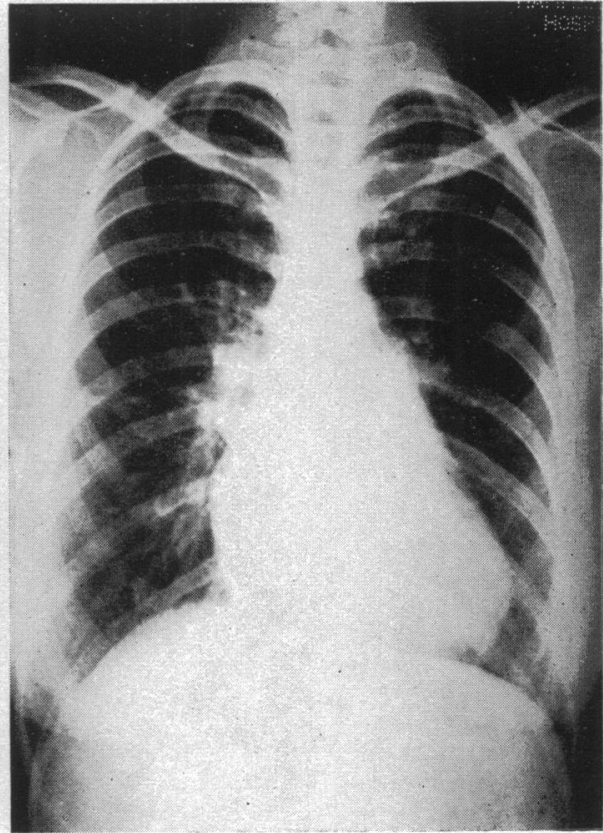

B

FIG. 5-(A) Selective pulmonary arteriogram of right lung of patient with pulmonary arterial pressure of $45 / 20 \mathrm{~mm}$. Hg. Slight enlargement of right main pulmonary artery and some narrowing and tortuosity of the peripheral basal branches. (B) Same patient as (A). Sixfoot plain radiograph of chest. Enlargement of the major branches of the pulmonary artery and narrowing of the basal peripheral branches can be seen.

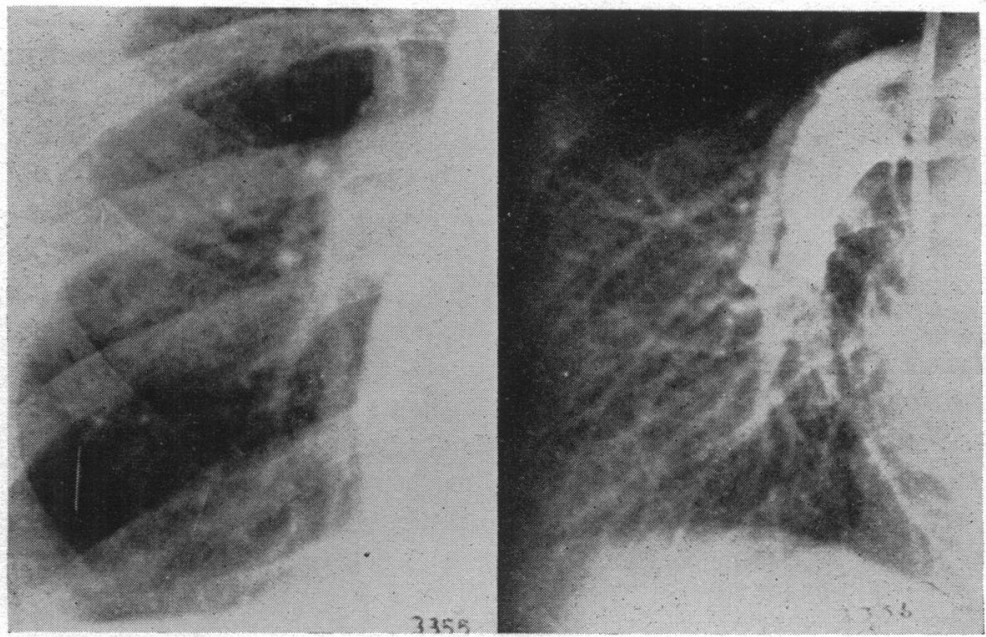

Fig. 6.-Comparison between the appearances of the pulmonary arteries of the right lower lobe in the plain radiograph and in the selective pulmonary arteriogram, in a patient with a pulmonary arterial pressure of $35 / 30 \mathrm{~mm}$. Hg. Slight narrowing of the distal branches can be seen in both. 

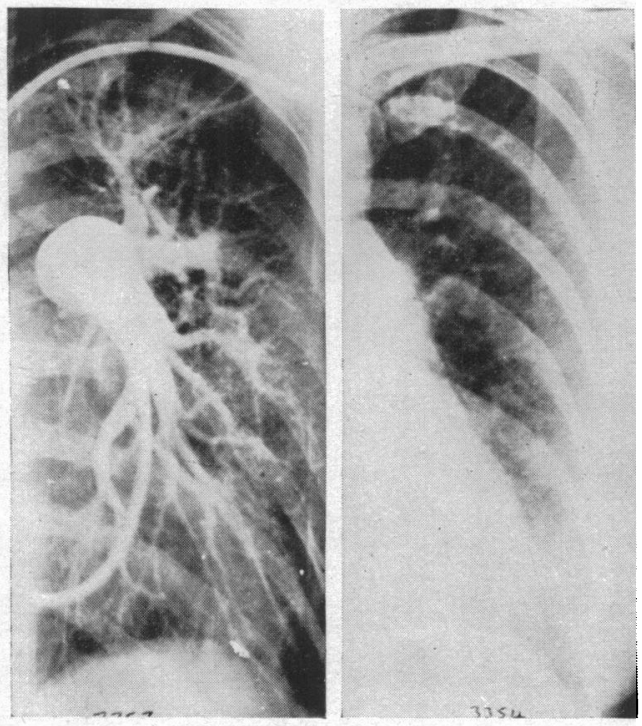

FIG. 7.-Same patient as Fig. 2. Comparison between the appearances of the left pulmonary arteries in the plain radiograph and in the selective pulmonary arteriogram. Enlargement of the left main pulmonary artery and marked narrowing of the distal branches, involving lower and mid zones, can be seen.

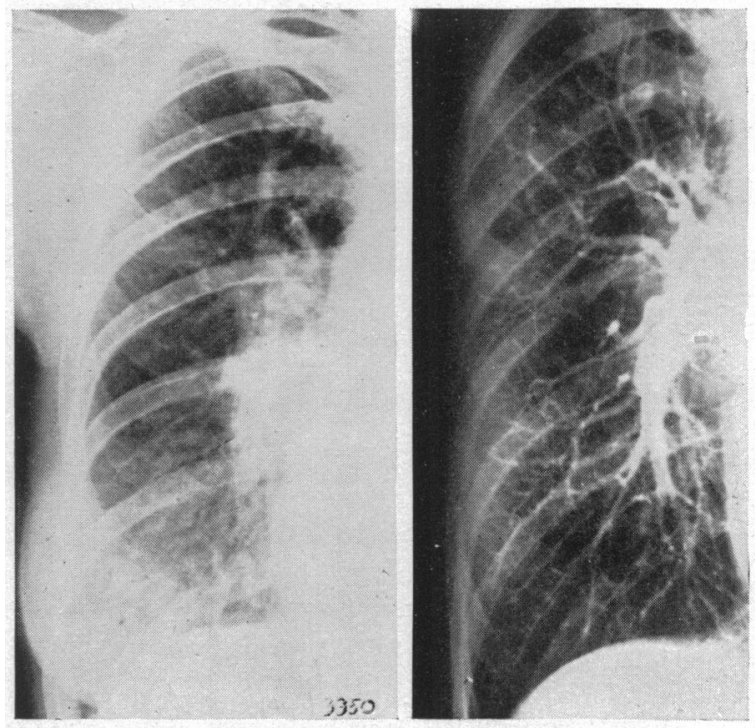

FIG. 8.-Comparison between the appearances of the pulmonary arteries in the right lung on the plain radiograph and in the selective pulmonary arteriogram, in a patient with a pulmonary arterial pressure of $60 / 40$ $\mathrm{mm}$. Hg. Enlargement of the main pulmonary artery is associated with generalized narrowing of peripheral branches. A fine mottling, which is not arterial in nature, can be seen at the right base in the plain film.

changes, while these abnormalities were usually absent in subjects with normal or only slightly raised pressures. Arterial changes were always present when the systolic pressure in the pulmonary artery was greater than $40 \mathrm{~mm}$. Hg. There were 8 patients with a systolic pressure greater than $80 \mathrm{~mm}$. $\mathrm{Hg}$, all of whom had widespread narrowing of the peripheral pulmonary artery branches (Grade II). There were 6 patients with a normal arterial pattern and normal pressures: one of them had severe symptoms, and at operation tight mitral stenosis was confirmed and valvotomy has been followed by marked improvement.

The systolic pulmonary arterial pressure to the nearest $5 \mathrm{~mm}$. $\mathrm{Hg}$ has been compared with the grade of symptoms, with the clinical grade of pulmonary hypertension, with the grade of arterial changes and with the cardiographic grade of right ventricular hypertrophy respectively (Fig. 10). The correlation between systolic pressure in the pulmonary artery and arterial changes was good. The correlation between the physical signs of pulmonary hypertension and pulmonary arterial pressure was rather better than that between symptoms and pressure, but it will be noted that systolic pressures of over $70 \mathrm{~mm}$. $\mathrm{Hg}$ were never associated with symptoms of less than Grade III severity, whereas Grade III symptoms were frequently found in association with pressures below 70 and sometimes below $50 \mathrm{~mm}$. $\mathrm{Hg}$. Correlation between systolic pressure in the pulmonary artery and electrocardiographic signs of right ventricular hypertrophy was poor. Correlation between pulmonary arterial mean pressure and grade of arterial changes was the same as when the systolic pressure was used.

\section{Discussion AND CONClusions}

The results indicate that narrowing of the peripheral pulmonary arteries, in association with enlargement of the main and proximal branches, occurs in patients with mitral stenosis and pul- 


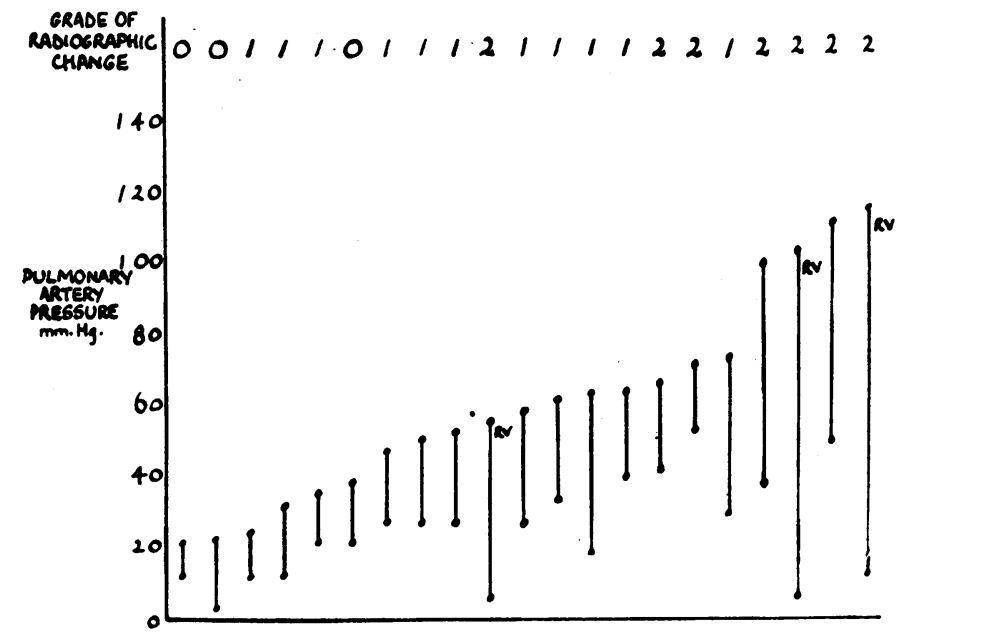

Fig. 9.-Comparison between the pulmonary arterial pressure and the plain film appearances of the pulmonary arteries in 21 patients with mitral stenosis, upon whom angiocardiography was not performed. The extent of the arterial changes seen on the plain radiograph is shown at the top of the chart.

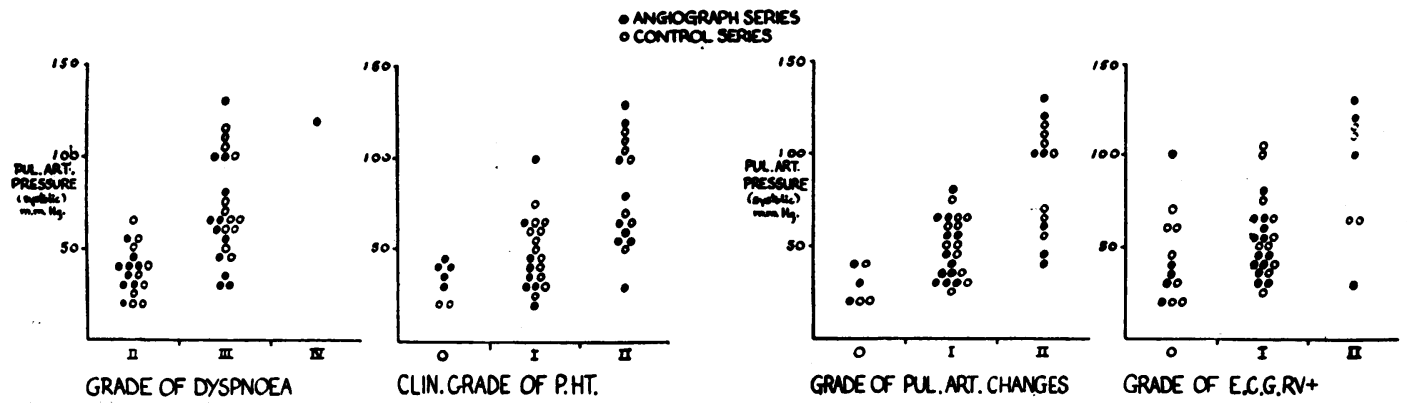

FIG. 10.-The systolic pulmonary arterial pressure (to the nearest $5 \mathrm{~mm}$.) in 43 patients, plotted against the grade of dyspncea on effort (New York Heart Association classification), the clinical grade of pulmonary hypertension, the grade of pulmonary arterial changes seen on the plain radiograph, and the electrocardiographic grade of right ventricular hypertrophy, respectively.

Closed circle represents patient with angiocardiogram. Open circle represents patient without angiocardiogram. P.H.T. = pulmonary hypertension. R.V.+ =right ventricular hypertrophy.

monary hypertension. These changes can be detected by careful inspection of a plain radiograph of the chest, and their extent is a guide to the level of the pulmonary arterial pressure. Although some overlap inevitably occurs, patients can be placed in three groups: (1) a "minimal " group in which the systolic pulmonary arterial pressure is below $40 \mathrm{~mm} . \mathrm{Hg}$, and the arterial changes are absent or slight; (2) an intermediate group, in which the pressures range approximately from 40-70 $\mathrm{mm}$. $\mathrm{Hg}$, and arterial changes are always present, usually confined to the bases; and (3) a severe group in which pulmonary arterial systolic pressures of more than $70 \mathrm{~mm} . \mathrm{Hg}$ and the arterial changes were widespread.

In no case have changes been seen in the mid-zones or apices of the lungs in the absence of concomitant basal changes, indicating that the arterial narrowing begins at the bases and then involves progressively more and more of the pulmonary arterial tree. Harrison (1953) has shown a similar distribution of organic narrowing on post-mortem angiocardiograms in subjects with mitral stenosis and severe pulmonary hypertension. He has also noted the absence of such changes in some cases 
known to have had high pulmonary arterial pressures. In these, active constriction during life must have been the cause of the narrowing.

It is interesting to note that the level in the pulmonary arterial tree where we observed narrowing is that at which the arteries have a predominantly muscular wall, while the dilated proximal arteries have elastic walls with relatively little muscle.

In our view the presence of arterial changes must be considered as one of the indications for valvotomy, since it is very probable that the process is progressive and will lead to a further rise in the pulmonary arterial pressure and deterioration in effort tolerance. Absence of radiological arterial changes and of pulmonary hypertension is unusual in the presence of severe symptoms and occurred in only one patient, in whom operation confirmed tight mitral stenosis.

It is suggested that the term " pulmonary congestion" be confined to the appearances seen in congestive heart failure and pulmonary œdema. In severe mitral stenosis without failure the main pulmonary arteries are enlarged, but the peripheral branches are actively narrowed rather than passively congested: the term congested pulmonary arteries is therefore incorrect.

Recognition of the arterial changes on the plain radiograph permits greater accuracy in the estimation of the pulmonary arterial pressure than has hitherto been possible at the bedside by clinical means. Cardiac catheterization may therefore be omitted in many patients, unless special problems are present.

\section{SUMMARY}

Fifty-one patients with mitral stenosis and varying degrees of pulmonary hypertension have been studied. In 31 of these, the pulmonary vascular pattern was investigated by venous angiocardiography or pulmonary arteriography.

In patients with pulmonary hypertension, the main arteries were found to be enlarged and the distal branches narrowed, irregular, and tortuous, especially in the lower lobes. The severity and extent of these changes bore a close relation to the degree of pulmonary hypertension.

The changes shown by angiocardiography could be detected on the plain film and were a better guide to the pulmonary arterial pressure than were the symptoms or clinical signs. The cardiographic signs of right ventricular hypertrophy gave little indication of the degree of pulmonary hypertension.

We wish to acknowledge the help of Professor J. McMichael and Dr. C. V. Harrison in the preparation of the paper, and to thank Mrs. Angela Birbeck for the tables, and Mrs. Connolly and Mr. Kemp for the radiological reproductions.

\section{REFERENCES}

Actis-Dato, A., Angelino, P. F., and Zambelli, E. (1952). Minerva Medica., 43, 693.

Ball, J. D., Kopelman, H., and Witham, A. C. (1952). Brit. Heart J., 14, 363.

Bayliss, R. I. S., Etheridge, M. J., and Hyman, A. L. (1950a). Lancet, 2, 889.

, Kelly, H. G., McMichael, J., and Reid, E. A. S. (1950b). Brit. Heart J., 12, 317.

Dexter, L., Dow, J. W., Haynes, F. W., Whittenberger, J. L., Ferris, B. G., Goodale, W. T., and Hellems, H. K. (1950). J. clin. Invest., 29, 602.

Eliasch, H. (1952). Scand. J. clin. lab. Invest., 4. Supplement 4.

Goodwin, J. F., Steiner, R. E., and Lowe, K. G. (1952). J. Fac. Radiol., 4, 21.

Harrison, C. V. (1953). Personal Communication.

Henry, E. W. (1952). Brit. Heart J., 14, 406.

Holling, H. E. (1952). Brit. med. Bull., 8, 358.

Kerley, P. (1951). In Shanks, S. C. and Kerley, P. (ed.) Textbook of X-ray Diagnosis. 2nd. ed., Vol. 11, p. $68,404$.

Larabee, W. S., Parker, R. L., and Edwards, J. E. (1949). Proc. Mayo Clin., 24, 316.

Lewis, B. M., Gorlin, R., Houssay, H. E. J., Haynes, F. W., and Dexter, L. (1952). Amer. Heart J., 43, 2.

New York Heart Association (1939). Nomenclature and Criteria for Diagnosis of Diseases of the Heart. New York: N.Y. Tuberculosis and Health Association.

Parker, F., and Weiss, S. (1936). Amer. J. Path., 12, 573.

Steiner, R. E., and Goodwin, J. F. (1953). J. Fac. Radiol. (in press). 